\title{
"Gênero" para um dicionário marxista: a política sexual de uma palavra*
}

\author{
Donna Haraway **
}

\begin{abstract}
Resumo
A autora conta suas desventuras teóricas após aceitar escrever um verbete sobre "gênero" para um dicionário marxista reputado. Em suas próprias palavras: "Além disso, mesmo se Marx e Engels - ou até Gayle Rubin - não se aventuraram pela sexologia, medicina ou biologia em suas discussões sobre sexo/gênero, ou sobre a questão da mulher, eu sabia que teria de fazê-lo. Ao mesmo tempo, estava claro que outras GRANDES correntes dos escritos feministas modernos sobre sexo, sexualidade e gênero se entrelaçavam constantemente mesmo com as mais modestas interpretações de minha encomenda. A maioria delas, talvez especialmente as correntes psicanalítica e literária do feminismo francês e inglês, não aparece em meu verbete sobre Geschlecht. De modo geral, o verbete abaixo focaliza os escritos das feministas norte-americanas. Este não é um escândalo trivial."
\end{abstract}

Palauras-chave: Gênero, Marxismo, Teoria Feminista, Teoria Feminista Norte-Americana.

\footnotetext{
" "Gender" for a Marxist Dictionary: the Sexual Politics of a Word. In: Simians, Cyborgs, and Women. The Reinvention of Nature. Londres, Free Association Books Ltd., 1991, capítulo 7, pp.127-148. (Tradução: Mariza Corrêa; Revisão: Iara Beleli.) O Comitê Editorial dos cadernos pagu agradece a especial permissão da Free Association Books Ltd. para traduzir este capítulo.

${ }^{* *}$ Universidade da Califórnia, Santa Cruz.
} 
"Gênero" para um dicionário marxista

"Gender" for a Marxist Dictionary:

the Sexual Politics of a Word

\begin{abstract}
The misadventures of the Author in writing about a "key-word" for a famous marxist dictionary are recounted here. In her own words: "Also, even if Marx and Engels - or Gayle Rubin, for that matter had not ventured into sexology, medicine, or biology for their discussions of sex/gender or the woman question, I knew I would have to do so. At the same time, it was clear that other BIG currents of modern feminist writing on sex, sexuality, and gender interlaced constantly with even the most modest interpretation of my assignment. Most of those, perhaps especially the French and British feminist psychoanalytic and literary currents, do not appear in my entry on Geschlecht. In general, the entry below focuses on writing by US feminists. This is not a trivial scandal."
\end{abstract}

Key Words: Gender, Marxism, Feminist Theory, American Feminist Theory. 
Em 1983, Nora Rathzel, do coletivo feminista autônomo do jornal marxista independente Das Argument, da Alemanha Ocidental, escreveu pedindo-me um verbete sobre uma "palavra chave" para um novo dicionário marxista. Um grupo editorial do Das Argument havia empreendido o ambicioso projeto de traduzir para o alemão os vários volumes do Dictionnaire Critique du Marxisme $e^{1}$ e também de preparar um suplemento alemão à parte, que tratasse particularmente dos novos movimentos sociais, não tratados na edição francesa. ${ }^{2}$ Esses movimentos haviam produzido uma revolução internacional na teoria social crítica dos últimos vinte anos. Produziram também - e parcialmente foram produzidos por - revoluções na linguagem política no mesmo período. Como disse Rathzel,

Nós, isto é, o grupo editorial feminista, vamos sugerir algumas palavras-chave que estão ausentes e queremos que algumas outras sejam re-escritas, porque as mulheres não aparecem onde deveriam. ${ }^{3}$

Esta crítica sutil identificava uma importante arena da luta feminista - a canonização da linguagem, da política e das

1 LABICA, Georges e BENUSSEN, Gerard. (eds.) Dictionnaire critique du marxisme. 8 vols., Paris, Presses Universitaires de France, 1985.

2 O projeto era tão assustador que o "suplemento" separou-se do projeto de tradução e está a caminho como um trabalho em dois volumes com vida própria, o Marxistisches Wörterbuch, sob a organização geral de Wolfgang F. Haug do Institut für Philosophie, Freie Universität, Berlim. Há centenas de contribuições, da Alemanha e de vários outros países. A partir de uma lista feita em 1985, algumas das palavras-chave planejadas, de particular interesse para as feministas, são: Diskurs, Dritte Welt, Familie, Feminismus, feministische Theologie, Frauen, Frauenbewegung, Geschlecht, Homosexualität, Kulturarbeit, Kybernetik, Luxemburgismus, Marxismus-feminismus, Natur, Ökologie, Patriarchat, Postmodernismus, Rasse, Rassismus, Repräsentation, Sex/gender systems, Sexismus, Sexpol, Sisterhood, technologische Rationalität, weibliche Ästhetik e weibliche Bildung. Certamente este não era o vocabulário cotidiano de Marx e Engels. Mas ele, enfaticamente, cabe num dicionário marxista do final do século vinte.

3 Comunicação pessoal, 2 de dezembro de 1983. 
"Gênero" para um dicionário marxista

narrativas históricas nas práticas editoriais, incluídos aí os trabalhos básicos de referência.

"As mulheres não aparecem onde deveriam". As ambigüidades da expressão eram poderosas e tentadoras. Aqui estava uma oportunidade de participar da produção de um texto de referência. Eu teria de produzir cerca de cinco laudas sobre minha encomenda: sexo/gênero. Audaciosamente, escrevi aceitando a tarefa.

Havia um problema imediato: sou anglófona, com algum conhecimento útil, mas complicado, do alemão, do francês e do espanhol. Este conhecimento lingüístico distorcido reflete minha alocação política num mundo social distorcido pelos projetos hegemônicos dos Estados Unidos e a ignorância culposa dos cidadãos, particularmente os brancos, norte-americanos. $\mathrm{O}$ inglês, especialmente o inglês americano, distingue sexo e gênero. Esta distinção custou sangue na luta em várias arenas sociais, como o leitor poderá ver na discussão que se segue. O alemão tem apenas uma palavra, Geschlecht, que não é exatamente a mesma, seja para o inglês sexo, seja para gênero. Além disso, o projeto do dicionário, traduzindo os verbetes de autores estrangeiros para o alemão, propunha apresentar cada palavra-chave em alemão, chinês (em ideogramas e na transcrição), inglês, francês, russo (apenas na transcrição) e espanhol. As histórias entrelaçadas do marxismo e do imperialismo assumiam enorme proporção nessa lista. Cada palavra-chave iria herdar essas histórias.

Pelo menos eu sabia que o que estava acontecendo com sexo e gênero em inglês não era o mesmo que se passava com género, genre e Geschlecht. As histórias específicas do movimento de mulheres nas vastas áreas do mundo nas quais essas linguagens eram parte da política vivida eram as razões principais das diferenças. Os velhos gramáticos, antes hegemônicos incluídos aí os sexologistas - tinham perdido o controle sobre gênero e seus irmãos - que proliferavam. A Europa e a América do Norte não podiam começar a disciplinar o destino de suas linguagens imperializantes no século vinte. Entretanto, eu não 
tinha nenhuma pista sobre o que fazer com meu problema sexo/gênero em russo ou chinês. Aos poucos, ficou claro que também tinha poucas pistas sobre o que fazer com sexo/gênero em inglês, mesmo nos Estados Unidos, e muito menos no mundo anglófono. Há tantos tipos de inglês, apenas nos Estados Unidos, $e$ todos eles subitamente pareciam relevantes para essas cinco laudas de texto para um dicionário marxista alemão que estava se separando de seus pais franceses para prestar atenção aos novos movimentos sociais. Meu inglês era marcado por raça, geração, gênero (!), região, classe, educação e história política. Como poderia este inglês ser a minha matriz para sexo/gênero em geral? Existia alguma coisa, mesmo em palavras, se em nada mais, como "sexo/gênero em geral"? Obviamente não. Esses não eram problemas novos para quem escreve para dicionários mas me senti, bem, galinha, politicamente galinha. Mas as editoras trabalham e um prazo final estava próximo. Era tempo de arrancar uma pena e escrever. Afinal de contas, no final do século vinte, somos literalmente a corporificação de tecnologias da escrita. Isto é parte da implosão de gênero no sexo e na linguagem, na biologia e na sintaxe, possibilitada pela tecnociência ocidental.

Em 1985 fiquei moderadamente satisfeita ao saber que o grupo editorial realmente queria um verbete sobre o sistema de sexo/gênero. Isto ajudava: havia um locus textual específico do primeiro uso do termo - o surpreendente ensaio de Gayle Rubin, escrito quando ela era uma estudante de pós-graduação na Universidade de Michigan, "The traffic in women: notes on the political economy of sex" [Tráfico de mulheres: notas sobre a economia política do sexo]. ${ }^{4}$ Eu poderia acompanhar o destino do "sistema de sexo/gênero" na explosão dos escritos feministas socialistas e marxistas influenciados por Rubin. Esta idéia foi só um breve consolo. Primeiro, os editores decidiram que cada

4 RuBIN, Gayle. The Traffic in Women: Notes on the Political Economy of Sex. In: REITER, Rayna Rapp. (ed.) Toward an Anthropology of Women. New York, Monthly Review, 1975 
"Gênero" para um dicionário marxista

palavra-chave deveria ser posta em relação à obra de Marx $e$ Engels, tivessem eles ou não utilizado os mesmos termos. Creio que Marx se divertiria ao ver a mão morta guiando o cursor vivo exibido no terminal de computador. Em segundo lugar, os que adotaram a formulação de Rubin, o fizeram a partir de variadas histórias, incluindo interesses acadêmicos e políticos. As feministas socialistas brancas norte-americanas deram origem ao conjunto mais óbvio de textos para acompanhar literalmente o "sistema de sexo/gênero". Isto era em si mesmo um problema complexo, não uma solução. Boa parte da teoria feminista mais provocativa dos últimos vinte anos insistira nas relações entre sexo e raça de maneira a problematizar as dores do parto do sistema de sexo/gênero num discurso mais focalizado no entrelaçamento de gênero e classe. ${ }^{5}$ Muito raramente a teoria feminista juntou analiticamente raça, sexo/gênero e classe - apesar das melhores intenções, das palavras de ordem dos autores e das observações nos prefácios de livros. Além disso, as feministas têm tanta razão em argumentar a favor de um sistema de raça/gênero quanto no argumento de um sistema de sexo/gênero, e os dois não são o mesmo tipo de movimento analítico. E o que aconteceu com classe? Cresce a evidência da necessidade de uma teoria da "diferença" cuja geometria, paradigmas e lógica escapem aos

${ }^{5}$ Uma curiosa questão lingüística se apresenta aqui: não há marcador para distinguir raça (biológica) de raça (cultural) como existe para sexo (biológico) e gênero (cultural), ainda que os binarismos natureza/cultura e biologia/sociedade permeiem o discurso ocidental sobre raça. Esta situação lingüística ilumina a recente e controversa entrada de gênero no léxico político, por oposição ao gramatical. A não-naturalidade de raça - ela é sempre e inteiramente uma construção arbitrária, cultural - pode ser enfatizada pela falta de um marcador lingüístico. Mas é também fácil o colapso total da categoria raça no biologismo, é um convite lingüístico. Todas essas questões continuam a depender de um funcionamento não examinado da lógica aristotélica, producionista, fundamental a boa parte do discurso ocidental. Nessa matriz lingüística, política e histórica, a matéria e a forma, o ato e a potência, o material bruto e o produto acabado representam em escala crescente seus dramas de produção e apropriação. Aqui é onde os sujeitos e objetos nascem e reencarnam indefinidamente. 
binarismos, à dialética, aos modelos natureza/cultura de todo tipo. Do contrário, três serão sempre reduzidos a dois que logo se tornam um solitário um na vanguarda. E ninguém aprende a contar até quatro. Essas coisas têm importância política.

Além disso, mesmo se Marx e Engels - ou até Gayle Rubin não se aventuraram pela sexologia, medicina ou biologia em suas discussões sobre sexo/gênero, ou sobre a questão da mulher, eu sabia que teria de fazê-lo. Ao mesmo tempo, estava claro que outras GRANDES correntes dos escritos feministas modernos sobre sexo, sexualidade e gênero se entrelaçavam constantemente mesmo com as mais modestas interpretações de minha encomenda. A maioria delas, talvez especialmente as correntes psicanalítica e literária do feminismo francês e inglês, não aparece em meu verbete sobre Geschlecht. De modo geral, o verbete abaixo focaliza os escritos das feministas norte-americanas. Este não é um escândalo trivial. ${ }^{6}$

\footnotetext{
${ }^{6}$ Embora não mutuamente exclusiva, a linguagem de "gênero" no discurso feminista euro-americano é usualmente a linguagem de "posição de sujeito sexuado" e "diferença sexual" na escrita européia. Sobre o feminismo marxista britânico e seu tratamento do "sujeito sexuado no patriarcado", ver KUHN, Annette e WolPE, AnnMarie. (eds.) Feminism and Materialism. London, Routledge \& Kegan Paul, 1978; Marxist-Feminist Literature Collective. Women's Writing. Ideology and Consciousness 1(3), 1978; BROWN, Beverley e ADAMS, Parveen. The Feminine Body and Feminist Politics. $\mathrm{m} / \mathrm{f}$ 3, 1979; a revista $\mathrm{m} / \mathrm{f}$ e BARRET, Michèle. Women's Oppression Today. London, Verso, 1980. As posições feministas-socialistas alemãs sobre a sexualização enfatizam a dialética da atuação auto-construtora das mulheres, determinações sociais já estruturadas $e$ re-estruturações parciais. Esta literatura examina como as mulheres constroem a si mesmas no interior de estruturas existentes, de modo a encontrar o ponto no qual seja possível a mudança. Se as mulheres são teorizadas como vítimas passivas do sexo e do gênero como um sistema de dominação, nenhuma teoria da liberação seria possível. Portanto, não se deve permitir que o construcionismo social na questão de gênero se torne uma teoria de determinismo fechado. (HAUGG, Frigga. (ed.) Frauenformen: alltagsgeschichten und entwurf einer theorie weiblicher sozialisation. Berlim, Argument Sonderbag 45, 1980 e Frauen un theorie. Das argument 136 (11/12), 1982; HAUGG, Frigga et alii. Sexualisierung: Frauenformen 2. Berlim, Argument-Verlag, 1983 e Female Sexualization: a Collective Work of Memory. London, Verso, 1987; Mouffe, Chantal. The Sex-
} 
"Gênero" para um dicionário marxista

Assim, o que se segue mostra os saltos descontínuos de continuadas reconstruções ao longo de seis anos. As lacunas e as pontas, tanto quanto a forma genérica de um verbete de enciclopédia, deveriam chamar a atenção para os processos políticos e convencionais da uniformização. As passagens sem problemas são provavelmente as mais reveladoras de todas; elas realmente escondem um campo muito conflitivo. Talvez eu apenas precisasse de uma lição concreta sobre quão problemático um verbete sobre uma "palavra-chave" deve ser. Mas suspeito que minhas irmãs e outros camaradas também tenderam, às vezes, a simplesmente acreditar no que leram num texto de referência, ao invés de lembrarem que esta forma de escrita é mais um modo de habitar mundos possíveis - tentativamente, esperançosamente, polifônicamente e finitamente. Por último, o verbete sobre a palavra-chave excedeu as cinco laudas e a galinha ficou sem penas. $O$ corpo se tornara inteiramente texto $e$ o instrumento de inscrição não foi uma pena, mas um ratinho. A

Gender System and the Discursive Construction of Women's Subordination. Rethinking Ideology, Berlim, Argument Sonderband 84, 1983). Na busca de uma teoria da experiência, sobre como as mulheres ativamente se corporificam, as mulheres do coletivo que escreveu as publicações do Frauenformen insistiram numa prática descritiva/teórica que mostrasse "as maneiras como vivenciamos nossos corpos" (HAUGG, F. et alii. Female Sexualization... Op. cit., p.30). Elas criaram um método chamado "trabalho da memória" que enfatiza narrativas escritas, coletivamente criticadas, a respeito de "uma estranha", de um eu passado "lembrado", ao mesmo tempo em que problematizam as suposições auto-ilusórias da auto-biografia e de outros relatos causais. O problema é dar conta da emergência do "sexual como o processo que produz a alocação das mulheres nas, e sua subordinação às, práticas sociais determinadas" (p.33). Ironicamente, auto-constituídas como sexualizadas, como mulher, as mulheres não podem ser responsáveis perante si mesmas ou a sociedade (p.27). Como todas as teorias de sexo, sexualidade e gênero, revisadas neste esforço para escrever para uma obra de referência padrão que inevitavelmente funciona para canonizar alguns sentidos em detrimento de outros, as versões da Frauenform insistem em gênero como gerúndio ou verbo, e não como substantivo. Para as feministas, gênero significa o fazer e desfazer de "corpos" num mundo de contestações; um relato de gênero é uma teoria da experiência como corporificação significativa e significante. 
nova genitália da escrita suprirá o analista com suas metáforas, assim como o sistema de sexo/gênero adquire outras formas em outros mundos de diferenças marcadas pelo poder e com suas conseqüências.

\section{Palavra-chave}

Gender (inglês), Geschlecht (alemão), Genre (francês), Género (espanhol)

[A raiz da palavra em inglês, francês e espanhol é o verbo latino generare, gerar, e a alteração latina gener-, raça ou tipo. Um sentido obsoleto de "to gender" em inglês é "copular" (Oxford English Dictionary). Os substantivos "Geschlecht", "Gender", "Genre" e "Género" se referem à idéia de espécie, tipo e classe. "Gênero" em inglês tem sido usado neste sentido "genérico", continuadamente, pelo menos desde o século quatorze. Em francês, alemão, espanhol e inglês, "gênero" refere-se a categorias gramaticais e literárias. As palavras modernas em inglês e alemão, "Gender" e "Geschlecht', referem diretamente conceitos de sexo, sexualidade, diferença sexual, geração, engendramento e assim por diante, ao passo que em francês e em espanhol elas não parecem ter esses sentidos tão prontamente. Palavras próximas a "gênero" implicam em conceitos de parentesco, raça, taxonomia biológica, linguagem e nacionalidade. O substantivo "Geschlecht' tem o sentido de sexo, linhagem, raça e família, ao passo que a forma adjetivada "Geschlechtlich" significa, na tradução inglesa, sexual e marcado pelo gênero. Gênero é central para as construções e classificações de sistemas de diferença. A diferenciação complexa e a mistura de termos para "sexo" e "gênero" são parte da história política das palavras. Os significados médicos acrescentados a "sexo" se somam progressivamente a "gênero", no inglês, através do século vinte. Significados médicos, zoológicos, gramaticais e literários têm, todos, sido contestados pelos feminismos modernos. Os significados compartilhados das categorias raciais e sexuais de 
"Gênero" para um dicionário marxista

gênero apontam para as histórias modernas das opressões coloniais, racistas e sexuais entrelaçadas nos sistemas de produção $e$ inscrição do corpo e seus conseqüentes discursos libertários e de oposição. A dificuldade de acomodar as opressões racial e sexual nas teorias marxistas de classe encontra paralelo na própria história das palavras. Este pano de fundo é essencial para a compreensão das ressonâncias do conceito teórico do "sistema de sexo/gênero" construído pelas feministas ocidentais anglófonas nos anos setenta. ${ }^{7} \mathrm{Em}$ todas as suas versões, as teorias feministas de gênero tentam articular a especificidade da opressão das mulheres no contexto de culturas nas quais as distinções entre sexo e gênero são marcantes. Quão marcantes depende de um sistema relacionado de significados reunido em torno de uma família de pares de oposição: natureza/cultura, natureza/história, natural/humano, recursos/produtos. Esta interdependência capital de um campo político-filosófico ocidental de oposições binárias - funcionalmente, dialeticamente, estruturalmente ou psicanaliticamente compreendidas - problematiza as alegações de utilização universal de conceitos relacionados a sexo e gênero; esta questão é parte do debate em andamento sobre a relevância

\footnotetext{
7 Joan Scott (pp.28-50) deu um tratamento incisivo ao desenvolvimento de gênero como uma categoria teórica na disciplina da história. Ela observou a longa história dos jogos de palavras com as diferenças de gênero gramaticais no uso de alusões figuradas ao sexo ou ao caráter. (SCOTT, Joan Wallach. Gender and the Politics of History. New York, Columbia University Press, 1988, p.28). Scott citava como epígrafe a insistência do Fowler's Dictionary of Modern English Usage's de que usar gênero para significar o sexo masculino ou feminino era ou um equívoco ou uma piada. As ironias deste tipo são abundantes. Um dos benefícios da herança gramatical nos usos feministas de gênero é que, nesse domínio, "gênero é entendido como uma maneira de classificar fenômenos, um sistema de distinções que tem aprovação social, e não uma descrição objetiva de traços inerentes". ID., IB., p.29. [Existe tradução brasileira de partes do livro: Prefácio à Gender and the Policits of History. cadernos pagu (3), Núcleo de Estudos de Gênero - Pagu/Unicamp, 1994, pp.9-26; Gênero como categoria útil de análise histórica. Educação e Realidade 16(2), Porto Alegre, julho/dezembro de 1990, pp.5-22.]
} 
transcultural das versões euro-americanas da teoria feminista. ${ }^{8} \mathrm{O}$ valor de uma categoria analítica não é necessariamente anulado pela consciência crítica de sua especificidade histórica e de seus limites culturais. Mas os conceitos feministas de gênero colocam de modo agudo os problemas da comparação cultural, da tradução lingüística e da solidariedade política.]

\section{História}

\section{Articulação do problema nos escritos de Marx e Engels}

Num sentido crítico, político, o conceito de gênero foi articulado e progressivamente contestado $e$ teorizado no contexto dos movimentos de mulheres feministas do pós-guerra. O conceito feminista moderno de gênero não se encontra nos escritos de Marx e Engels, embora seus escritos e outras práticas, e as de outros da tradição marxista, tenham oferecido instrumentos importantes, assim como barreiras, para as teorizações posteriores sobre gênero. Apesar de importantes diferenças, todos os significados modernos de gênero se enraízam na observação de Simone de Beauvoir de que "não se nasce mulher" $e$ nas condições sociais do pós-guerra que possibilitaram a construção das mulheres como um coletivo histórico, sujeito-em-processo. Gênero é um conceito desenvolvido para contestar a naturalização da diferença sexual em múltiplas arenas de luta. A teoria e a prática feminista em torno de gênero buscam explicar $e$ transformar sistemas históricos de diferença sexual nos quais "homens" $e$ "mulheres" são socialmente constituídos $e$ posicionados em relações de hierarquia e antagonismo. Já que o conceito de gênero está tão intimamente ligado à distinção

8 STRATHERN, Marlyn. The Gender of the Gift: problems with women and problems with society in Melanesia. Berkeley, University of California Press, 1988.

9 DE BEAUVOIR, Simone. Le deuxième sexe. Paris, Gallimard, 1949. [O segundo sexo. 2 vols., São Paulo, Difusão Européia do Livro, 1960, 1961. (Trad.: Sergio Milliet.)] 
"Gênero" para um dicionário marxista

ocidental entre natureza e sociedade ou natureza e história, via a distinção entre sexo e gênero, a relação das teorias feministas de gênero com o marxismo está vinculada à sorte dos conceitos de natureza e trabalho no cânone marxista e na teoria ocidental de modo mais geral.

As abordagens marxistas tradicionais não levaram a um conceito político de gênero por duas razões principais: primeiro, as mulheres, como os povos "tribais", existiam de maneira instável nas fronteiras do natural e do social nos escritos mais importantes de Marx e Engels, de modo que seus esforços para explicar a posição subordinada das mulheres foram minados pela categoria da divisão natural do trabalho, que se apóia numa heterossexualidade inquestionável; segundo, Marx e Engels teorizaram a relação econômica de propriedade como a base da opressão das mulheres no casamento, de modo que a subordinação das mulheres pudesse ser examinada em termos das relações capitalistas de classe, mas não em termos de uma política sexual específica entre homens e mulheres. O lugar clássico desse argumento está em Engels, em The Origins of the Family, Private Property and the State [A origem da familia, da propriedade privada e do estado]. ${ }^{10}$ A prioridade analítica da família como uma formação mediadora entre as classes $e$ o Estado, em Engels, "abarcava qualquer consideração independente da divisão dos sexos como uma divisão antagônica". ${ }^{11}$

Apesar de sua insistência na variabilidade histórica das formas familiares e na importância da questão da subordinação da

${ }^{10}$ Engels, Friedrich. [1884] The Origins of the Family, Private Property and the State, New York, International, 1972 (Trad.: Eleanor B. Leacock). [A origem da família, da propriedade privada e do Estado. Rio de Janeiro, Editorial Vitória, 1964. (Trad.: Leandro Konder.)]

${ }^{11}$ CowARD, Rosalind. Patriarchal Precedents: Sexuality and Social Relations. London, Routledge \& Kegan Paul, 1983, p.160. Para uma discussão mais abrangente dos conceitos de família e da questão da mulher no pensamento marxista, de 1848 até cerca de 1930, ver capítulos 5 e 6 . 
mulher, Marx e Engels não podiam historicizar sexo e gênero a partir do suposto da heterossexualidade como natural.

$A$ ideologia alemấ ${ }^{12}$ é a fonte principal da naturalização de Marx e Engels da divisão sexual do trabalho, na sua suposição de uma divisão pré-social do trabalho no ato sexual (relação heterossexual), seus supostos corolários naturais nas atividades reprodutivas de homens e mulheres na família e a conseqüente incapacidade de alocar, sem ambigüidades, as mulheres nas suas relações com os homens do lado da história e da sociedade. Nos Manuscritos econômicos e filosóficos de 1844, Marx refere-se à relação entre homens e mulheres como "as relações mais naturais entre seres humanos". ${ }^{13}$ Esta suposição persiste no volume I de $O$ Capital. ${ }^{14}$ Esta incapacidade de historicizar o trabalho das mulheres é paradoxal em vista do propósito de $A$ ideologia alemá $e$ de trabalhos subseqüentes de colocar a família numa posição central na história, como o lugar no qual as divisões sociais emergem. A dificuldade principal era uma incapacidade de historicizar o sexo; como a natureza, o sexo funcionava analiticamente como matéria-prima ou material bruto para $\mathrm{o}$ trabalho da história. Apoiando-se na pesquisa de Marx em seus escritos etnográficos ${ }^{15}$, a Origem de Engels sistematizou suas visões a respeito das transições vinculadas da família, das formas de propriedade, da organização da divisão do trabalho $e$ o Estado. Engels quase lançou as bases para teorizar a opressão específica das mulheres em sua curta observação de que uma

\footnotetext{
${ }^{12}$ MARX, Karl e ENGELS, F. The German Ideology. London, Lawrence \& Wishart, 1970, parte 1, Teses sobre Feuerbach. [A ideologia alemã. São Paulo, Martins Fontes, 1974.]

${ }^{13}$ MARX, Karl. The Economic and Philosophic Manuscripts of 1844. New York, International, 1964, p.134. [Manuscritos econômicos e filosóficos de 1844. 2.ed. São Paulo, Abril, 1978.]

${ }^{14}$ ID. Capital. Vol I. New York, Internacional, 1964, p.351. [O Capital. Volume I. Rio de Janeiro, Civilização Brasileira, 1976.]

${ }^{15}$ ID. The ethnological notebooks of Karl Marx. Assen, van Gorcun, 1972. (Trad. e ed.: Lawrence Krader.)
} 
"Gênero" para um dicionário marxista

análise inteiramente materialista da produção e reprodução da vida imediata apresenta uma característica dupla: a produção dos meios de existência e "a produção dos seres humanos". ${ }^{16}$ Uma exploração dessa segunda característica foi o ponto de partida de muitas feministas marxistas euro-americanas em suas teorias da divisão do trabalho por meio do sexo/gênero. ${ }^{17}$

A "questão da mulher" foi amplamente debatida em muitos dos partidos marxistas europeus no final do século dezenove $e$ início do século vinte. No contexto do Partido Social Democrático Alemão, foi escrita a outra das duas mais influentes abordagens marxistas sobre a posição das mulheres: a de August Bebel Woman under Socialism [As mulheres sob 0 socialismo.$^{18}$ Alexandra Kollontai inspirou-se em Bebel nas suas lutas pela emancipação da mulher na Rússia e na União Soviética; e, no interior da democracia social alemã, Clara Zetkin, líder do Movimento das Mulheres na Internacional Socialista, levou

\footnotetext{
${ }^{16}$ ENGELS, F. The origins of the family... Op. cit., p.71.
}

${ }^{17}$ RuBin, G. The Traffic in Women... Op. cit.; Young, Robert e LEWIDOW, Les. (eds.) Science, tecnology and the labour process. 2 vols., London, CSE e Free Association Books, 1981; Harding, Sandra. Why Has the Sex/Gender System Become Visible Only Now?. In: HARDING, S. e HinTikKA, Merill. (eds.) Discovering Reality: Feminist Perspectives on Epistemology, Metaphysics, Methodology, and Philosoply of Science. Dordrecht, Reidel, 1983 e The Science Question in Feminism. Ithaca, Cornell University Press, 1986; HARTSOCK, Nancy. The Feminist Standpoint: Developing the Ground for a Specifically Feminist Historical Materialism. In: HARDING, S. e HiNTIKKA, M. (eds.) Discovering Reality... Op. cit. e Money, Sex and Power. New York, Longman/Boston, Northeastern University Press, 1983; HARTMANN, Heidi. The Unhappy Marriage of Marxism and Feminism. In: SARGENT, Lydia. (ed.) Women and Revolution. Boston, South End, 1981; O'Brien, Mary. The Politics of Reproduction. New York, Routledge \& Kegan Paul, 1981; CHODOROW, Nancy. The Reproduction of Mothering: Psychoanalysis and the Sociology of Gender. Los Angeles, University of California Press, 1978; JAGgAR, Alison. Feminist Politics and Human Nature. Totowa, NJ, Roman and Allenheld, 1983.

${ }^{18}$ BEBEL, August. Woman under Socialism. New York, Schocken, [1971] 1993 (Trad.: D.De Leon). (Originalmente Women in the Past, Present and Future, 1878.) 
adiante a posição de Bebel no seu "The Question of Women Workers and Women at the Present Times" ["A questão das mulheres trabalhadoras e das mulheres no presente"], de $1889 .{ }^{19}$

\section{Problemas atuais}

\section{O paradigma da identidade de gênero}

A história das reformulações políticas de gênero pelas feministas ocidentais depois dos anos sessenta deve passar pela construção de sentidos e tecnologias de sexo e gênero nas ciências da vida normalizadoras, liberais, terapêutico-intervencionistas, empiricistas e funcionalistas, especialmente nos Estados Unidos, incluindo-se aí a psicologia, a psicanálise, a medicina, a biologia e a sociologia.

Gênero foi firmemente alocado a uma problemática individualista, dentro da ampla "incitação ao discurso" ${ }^{20}$, à sexualidade característica da sociedade burguesa, dominada pelos homens, e racista. Os conceitos e tecnologias da "identidade de gênero" foram produzidos a partir de vários componentes: uma leitura instintualista de Freud; o foco na psicopatologia $e$ somatologia sexual dos grandes sexologistas do século dezenove (Krafft-Ebing, Havelock Ellis) e seus seguidores; o contínuo desenvolvimento da endocrinologia bioquímica e fisiológica desde os anos vinte; a psicobiologia de diferenças sexuais nascida da psicologia comparada; as inúmeras hipóteses de dimorfismo sexual hormonal, de cromossomos e neural, que convergiram nos anos cinqüenta; $e$ as primeiras cirurgias de redefinição de gênero

\footnotetext{
${ }^{19}$ MARX, Eleanor e Aveling, E. The Woman Question. London, Swann \& Sonnenschein, 1885-6; KollONTAI, Alexandra. Selected Writings. London, Allison \& Busby, 1977

${ }^{20}$ Foucault, Michel. [1976] The History of Sexuality. Vol. I: An Introduction. New York, Pantheon, 1978. [História da sexualidade. Vol. I: A vontade de saber. Rio de Janeiro, Graal, 1979. (Trad.: Maria Thereza da Costa Albuquerque e J.A. Guilhon Albuquerque.)]
} 
"Gênero" para um dicionário marxista

por volta de $1960 .{ }^{21}$ A "segunda onda" da política feminista em torno dos "determinismos biológicos" versus "construcionismo social" e das bio-políticas das diferenças de sexo/gênero ocorrem no interior de campos discursivos pré-estruturados pelo paradigma de identidade de gênero, cristalizado nos anos cinqüenta $e$ sessenta. $\mathrm{O}$ paradigma da identidade de gênero era uma versão funcionalista e essencializante da percepção de Simone de Beauvoir nos anos quarenta, de que não se nasce mulher. É significativo que a construção do que poderia ser uma mulher (ou um homem) tornou-se um problema para os funcionalistas burgueses e os existencialistas pré-feministas no mesmo período histórico do pós-guerra no qual os fundamentos das vidas das mulheres num sistema dominado pelos homens, num mundo capitalista, estavam passando por reformulações básicas.

Em 1958, o Projeto de Pesquisa sobre Identidade de Gênero foi constituído no Centro Médico para o Estudo de Intersexuais e Transexuais, na Universidade da Califórnia, em Los Angeles (UCLA). O trabalho do psicanalista Robert Stoller ${ }^{22}$ discutia e generalizava as descobertas do projeto da UCLA. Stoller apresentou o termo "identidade de gênero" ao Congresso Internacional de Psicanálise, em Estocolmo, em 1963. ${ }^{23}$ Ele formulou o conceito de identidade de gênero no quadro da distinção biologia/cultura, de tal modo que sexo estava vinculado à biologia (hormônios, genes, sistema nervoso, morfologia) $e$ gênero à cultura (psicologia, sociologia). O produto do trabalho da cultura sobre a biologia era o centro, a pessoa produzida pelo gênero - um homem ou uma mulher. Começando nos anos cinqüenta, o psico-endocrinologista John Money, a partir da base

${ }^{21}$ LINDEN, Robin Ruth. The Social Construction of Gender: a Methodological Analysis of the Gender Identity Paradigm. Monografia de Graduação em Sociologia, Universidade da Califórnia, Santa Cruz, 1981.

22 StOLLER, Robert. Sex and Gender. Vol.I. New York, Science House, 1968; vol.II, New York, Jason Aronson, 1976.

${ }^{23}$ ID. A Contribution to the Study of Gender Identity. International Journal of Psychoanalysis 45, 1964. 
institucional da Clínica de Identidade de Gênero (criada em 1965) da Faculdade de Medicina da Universidade Johns Hopkins, com seu colega, Anke Ehrhardt, desenvolveu e popularizou a versão interacionista do paradigma de identidade de gênero na qual a mistura funcionalista de causas biológicas e sociais dava lugar a uma miríade de programas terapêuticos e de pesquisa sobre as "diferenças de sexo/gênero" - o que incluía cirurgia, aconselhamento, pedagogia, serviço social, e assim por diante. $\mathrm{O}$ livro de Money e Ehrhardt, Man and Woman, Boy and Girl [Homem e mulher, menino e menina], tornou-se um manual amplamente utilizado nas escolas secundárias $e$ nas universidades. ${ }^{24}$

A versão da distinção natureza/cultura no paradigma da identidade de gênero era parte de uma vasta reformulação liberal das ciências da vida e das ciências sociais no desmentido do pósguerra, feito pelas elites governamentais e profissionais do ocidente, das exibições de racismo biológico de antes da Segunda Guerra. Essas reformulações deixaram de interrogar a história sócio-política de categorias binárias tais como natureza/cultura, e também sexo/gênero, no discurso colonialista ocidental. Este discurso estrutura o mundo como objeto do conhecimento em termos da apropriação, pela cultura, dos recursos da natureza. Uma variada literatura recente, liberatória e oposicional, tem criticado esta dimensão epistemológica e lingüística, etnocêntrica, de dominação daqueles que habitam categorias "naturais" ou vivem nas fronteiras mediadoras dos binarismos (mulheres, povos de cor, animais, o meio ambiente não humano) ${ }^{25}$ As feministas da segunda onda cedo fizeram a crítica da lógica binária do par natureza/cultura, inclusive das versões dialéticas da narrativa

${ }^{24}$ MoNEY, John e EHRHARDT, Anke. [1972] Man and Woman, Boy and Girl. New York, New American Library, 1974.

${ }^{25}$ HARDING, S. The Science Question in Feminism. Op. cit., pp.163-96; FEE, Elizabeth. Critiques of Modern Science: the Relationship of Feminism to Other Radical Epistemologies. In: BlEIER, Ruth. (ed.) Feminist Approaches to Science. New York, Pergamon, 1986. 
"Gênero" para um dicionário marxista

marxista-humanista de dominação, apropriação ou mediação da "natureza" pelos "homens" através do "trabalho". Mas esses esforços hesitaram em ampliar inteiramente sua crítica à distinção derivada sexo/gênero. Esta distinção era muito útil no combate aos determinismos biológicos pervasivos constantemente utilizados contra as feministas em lutas políticas urgentes a respeito das "diferenças sexuais" nas escolas, nas editoras, nas clínicas e assim por diante. Fatalmente, nesse clima político limitado, aquelas primeiras críticas não historicizaram ou relativizaram culturalmente as categorias "passivas" de sexo ou natureza. Assim, as formulações de uma identidade essencial como homem ou como mulher permaneceram analiticamente intocadas e politicamente perigosas.

No esforço político e epistemológico para remover as mulheres da categoria da natureza e colocá-las na cultura como sujeitos sociais na história, construídas e auto-construtoras, o conceito de gênero tendeu a ser posto de quarentena contra as infecções do sexo biológico. Como conseqüência, a construção em andamento do que seria sexo ou do que seria mulher foi algo difícil de teorizar, a não ser como "má ciência", na qual a mulher emerge como naturalmente subordinada. "Biologia" tendia a denotar o corpo em si mesmo, e não um discurso social aberto à intervenção. Assim, as feministas argumentaram contra o "determinismo biológico" e a favor do "construcionismo social" e, no processo, tornaram-se menos capazes de desconstruir como os corpos, incluindo corpos sexuados e racializados, aparecem como objetos de conhecimento e lugares de intervenção na biologia. Alternativamente, as feministas, às vezes, afirmaram as categorias natureza e corpo como sítios de resistência às dominações da história, mas a afirmativa tendeu a obscurecer o aspecto de categoria e sobredeterminado de "natureza" ou de "corpo feminino" como um recurso ideológico oposicional. A natureza parecia simplesmente estar lá, uma reserva a ser preservada das violações da civilização em geral. Ao invés de marcar um pólo categorialmente determinado, "natureza" ou "corpo 
feminino" significam, de modo simplificado, o centro saudável da realidade, distinguível das imposições sociais do patriarcado, do imperialismo, do capitalismo, do racismo, da história, da linguagem.

Esta repressão da construção da categoria "natureza" pode ser, e tem sido, utilizada contra os esforços feministas para teorizar a atuação das mulheres e seu estatuto como sujeitos sociais.

Judith Butler ${ }^{26}$ argumentou que o discurso de identidade de gênero é intrínseco às ficções de coerência heterossexual e que o feminismo precisa aprender a produzir uma legitimidade narrativa para todo um conjunto de gêneros não coerentes. $\mathrm{O}$ discurso da identidade de gênero é também intrínseco ao racismo feminista, que insiste na não redutibilidade e na relação antagônica entre homens e mulheres coerentes. A tarefa é "desqualificar" as categorias analíticas, como sexo ou natureza, que levam à univocidade.

Isto exporia a ilusão de um centro interior organizador do gênero e produziria um campo de diferenças de gênero e de raça aberto à resignificação. Muitas feministas resistem a propostas como a de Butler por medo de perder um conceito de atuação para as mulheres, já que o conceito de sujeito murcha sob o ataque às identidades centradas e às ficções que as constituem. Butler, entretanto, argumentou que a ação ${ }^{27}$ é uma prática instituída num campo de limites possibilitadores. O conceito de um eu interior coerente adquirido (culturalmente) ou inato

${ }^{26}$ BUTLER, Judith. Gender Trouble: Feminism and the Subversion of Identity. New York, Routledge, 1989. [Problemas de gênero. Feminismo e subversão da identidade. Rio de Janeiro, Civilização Brasileira, 2003. (Trad.: Renato Aguiar).]

${ }^{27} \mathrm{NT}$ : Na tradução brasileira de A. Giddens, o termo agency aparece no glossário de seus conceitos como 'agência'. Por exemplo: “ 'Agência' diz respeito a eventos dos quais um indivíduo é o perpetrador no sentido de que ele poderia, em qualquer fase de uma dada seqüencia de conduta, ter atuado de modo diferente." [A construção da sociedade. São Paulo, Martins Fontes, 1989, p.7, (Trad.: Álvaro Cabral).] No entanto, ao longo do livro, o tradutor utiliza expressões mais usuais da língua portuguesa, como ação ou atuação, como faço aqui. 
"Gênero" para um dicionário marxista

(biológico) é uma ficção reguladora desnecessária - de fato, inibidora - aos projetos feministas de produzir e afirmar atuação $e$ responsabilidade complexas.

Uma "ficção reguladora" semelhante, básica para o conceito ocidental de gênero, insiste em que a maternidade é natural e a paternidade cultural: as mães fazem os bebês naturalmente, biologicamente. A maternidade salta à vista; a paternidade é inferida. Analisando conceitos e práticas de gênero entre os melanésios, Strathern ${ }^{28}$ esforçou-se para mostrar tanto a qualidade etnocêntrica da auto-evidente afirmativa ocidental de que "as mulheres fazem os bebês", quanto o caráter de inferência de qualquer visão. Ela apontou para o centro de produção da crença de que as mulheres fazem os bebês (e seu par, que os homens se fazem a si mesmos), intrínseca às formulações ocidentais de sexo $e$ gênero. Strathern argumentou que os homens $e$ as mulheres Hagen não existem em estado permanente como sujeitos $e$ objetos em contextos aristotélicos, hegelianos, marxistas ou freudianos. A atuação dos Hagen tem uma dinâmica e uma geometria diferentes. Para os ocidentais, uma conseqüência central dos conceitos de diferença de gênero é que uma pessoa pode ser transformada por outra em objeto e roubada de seu estatuto como sujeito. $\mathrm{O}$ estado adequado de uma pessoa ocidental é o de ter comando do ser, de ter e manter uma identidade centrada, como se fosse uma posse. Esta posse pode ser feita de variados materiais brutos ao longo do tempo, isto é, pode ser uma produção cultural, ou pode-se nascer com ela. A identidade de gênero é uma posse deste tipo. Não ter a propriedade do eu é não ser sujeito $e$, portanto, não ter capacidade de atuação. A atuação segue trilhas diferentes para os Hagen que, como pessoas,

são compostas de partes multiplamente marcadas pelo gênero, ou de pessoas multiplamente marcadas pelo

${ }^{28}$ STRATHERn, M. The Gender of the Gift.. Op. cit., pp.311-39. 
gênero, que interagem umas com as outras como doadores e receptores, mantendo o fluxo dos elementos através do corpo. $^{29}$

A dominação sexista entre pessoas pode ocorrer, $e$ ocorre sistematicamente, mas não pode ser descrita ou tratada usando-se os mesmos movimentos analíticos que seriam apropriados para muitos campos sociais ocidentais de sentido. ${ }^{30}$ Butler poderia cautelosamente - usar os argumentos etnográficos de Strathern para ilustrar uma maneira de dispersar a coerência de gênero sem perder o poder de atuação.

Assim, a utilidade tática corrente da distinção sexo/gênero nas ciências da vida e nas ciências sociais tem tido conseqüências importantes para boa parte da teoria feminista, vinculando-a a um paradigma liberal e funcionalista, apesar dos repetidos esforços para transcender esses limites através de um conceito de gênero inteiramente politizado e historicizado. Parcialmente, o problema está em não historicizar e relativizar o sexo e as raízes históricoepistemológicas da lógica da análise implícita na distinção sexo/gênero e em cada unidade do par. Neste nível, a limitação feminista moderna na teorização e na sua luta com as ciências da vida $e$ as ciências sociais é semelhante à incapacidade de Marx $e$ Engels de se desvencilharem da divisão sexual do trabalho natural na heterossexualidade, apesar de seu admirável projeto de historicizar a família.

O discurso das diferenças de sexo/gênero explodiu na literatura sociológica e psicológica nos Estados Unidos nos anos setenta e oitenta. (Isto pode ser visto, por exemplo, na ocorrência da palavra gênero como palavra-chave nos resumos dos artigos registrados nos Sociological Abstracts [de nenhum registro entre 1966 e 1970, a 724 registros entre 1981 e 1985] e nos Psychological

${ }^{29}$ Douglas, Mary. A Gentle Deconstruction. London Review of Books 4, maio de 1989, p.17.

${ }^{30}$ STRATHERn, M. The Gender of the Gift... Op. cit., pp.334-9. 
"Gênero" para um dicionário marxista

Abstracts [de 50 entradas como palavra chave de resumos entre 1966 e 1970 a 1326 entradas de 1981 a 1985].) A explosão é parte de um vigoroso debate político e científico a respeito da construção de sexo e de gênero como categorias e como realidades históricas emergentes, no qual os textos feministas tornaram-se preeminentes em meados dos anos setenta, principalmente na crítica ao "determinismo biológico" e à ciência $e$ tecnologia sexistas, especialmente a biologia e a medicina. Situadas no quadro epistemológico do binarismo natureza/cultura e sexo/gênero, muitas feministas (inclusive feministas socialistas $e$ marxistas) apropriaram a distinção sexo/gênero e o paradigma interacionista para argumentar a favor da primazia da culturagênero sobre a biologia-sexo, numa enorme gama de debates na Europa e nos Estados Unidos. Esses debates variaram desde as diferenças genéticas da capacidade matemática de meninos $e$ meninas, a presença e o significado de diferenças sexuais na organização dos neurônios, a relevância da pesquisa com animais para o comportamento humano, as causas da dominação masculina na organização da pesquisa científica, as estruturas e os usos padronizados sexistas na linguagem, os debates da sociobiologia, as lutas a respeito do significado das anomalias dos cromossomos sexuais até as semelhanças entre racismo e sexismo. Em meados dos anos oitenta, uma crescente suspeita sobre a categoria de gênero e sobre o binarismo sexo/gênero entrou na literatura feminista nesses debates. Esse ceticismo era parcialmente resultado dos desafios ao racismo nos movimentos euroamericanos de mulheres, de tal modo que algumas das raízes coloniais e racistas do quadro se tornaram mais claras. ${ }^{31}$

${ }^{31}$ Para levantamentos dos usos e sua crítica, ver SAYERS, Janet. Biological Politics: Feminist and Anti-Feminist Perspectives. London, Tavistock, 1982; HubBard, Ruth, Henifin, Mary Sue e Fried, Barbara. (eds.) Biological Woman, the Convenient Myth. Cambridge, Ma, Schenkman, 1982; BLEIER, Ruth. Science and Gender. A Critique of Biology and its Themes on Women. New York, Pergamon, 1984 e BlEIER, R. (ed.) Feminist Approaches... Op. cit.; FAUSTOSTERLING, Anne. Myths of Gender: Biological Theories about Women and Men. New York, Basic, 1985; KeSSLER, Suzanne e McKenNA, Wendy. Gender: an 
Donna Haraway

\section{O sistema sexo-gênero}

Outra tendência da teoria e da política feminista sobre sexo/gênero expressou-se através de apropriações de Marx e Freud, lidos a partir de Lacan e Lévi-Strauss, numa formulação influente do "sistema de sexo/gênero" feita por Gayle Rubin. ${ }^{32}$ Seu texto foi publicado na primeira antologia de antropologia feminista socialista/marxista nos Estados Unidos. Rubin, e as que a seguiam, adotaram a versão da distinção natureza/cultura, mas uma versão que devia menos às ciências sociais $e$ às ciências da vida empiricistas dos Estados Unidos e mais à psicanálise $e$ ao estruturalismo francês. Rubin examinava a "domesticação das mulheres" na qual as fêmeas humanas eram o material bruto na produção social de mulheres através da troca nos sistemas de parentesco controlados por homens na instituição da cultura humana. Ela definia o sistema sexo-gênero como o sistema de relações sociais que transformava a sexualidade biológica em produtos da atividade humana e no qual são satisfeitas as necessidades sexuais específicas daí historicamente resultantes. Ela reclamava uma análise marxista dos sistemas de sexo/gênero como produtos da atividade humana que podem ser transformados através da luta política. Rubin via a divisão sexual do trabalho e a construção psicológica do desejo (especialmente a formação edipiana) como fundamentos de um sistema de produção de seres humanos que atribuía aos homens direitos

Ethnomethodological Approach. Chicago, University of Chicago Press, 1978; ThORne, Barrie e Henley, Nancy. (eds.) Language and Sex: Difference and Dominance. Rowley, Ma, Newbury, 1975; WeSt, Candance e ZIMMERMANN, D.H. Doing Gender. Gender and Society 1(2), 1987; MorawsKI, J.G. The Troubled Quest for Masculinity, Femininity and Androginy. Review of Personality and Social Psychology 7, 1987; Brighton Women and Science Group. Alice Through the Microscope. London, Virago, 1980; LOWE, Marian e HuBBARD, Ruth. (eds.) Woman's Nature: Rationalizations of Inequality. New York, Pergamon, 1983; Lewontin, R.C., Rose, Steven e Kamin, Leon J. Not in Our Genes. Biology, Ideology, and Human Nature. New York, Pantheon, 1984

${ }^{32}$ Rubin, G. The Traffic in Women... Op. Cit. 
"Gênero" para um dicionário marxista

sobre as mulheres que elas próprias não tinham sobre si mesmas. Para garantir a sobrevivência material, quando homens $e$ mulheres não podem realizar o trabalho um do outro, e para satisfazer estruturas profundas de desejo no sistema de sexo/gênero no qual homens trocam mulheres, a heterossexualidade é obrigatória. A heterossexualidade obrigatória é, portanto, central na opressão das mulheres.

Se o sistema de propriedade sexual fosse reorganizado de tal modo que os homens não tivessem direitos absolutos sobre as mulheres (se não houvesse troca de mulheres), $e$ se não houvesse gênero, todo o drama edipiano se tornaria uma relíquia. Em suma, o feminismo deve reclamar uma revolução no parentesco. ${ }^{33}$

Adrienne Rich ${ }^{34}$ também postulou que a heterossexualidade compulsória está na raiz da opressão das mulheres. Rich utilizou "o continuum lésbico" como uma potente metáfora para estabelecer uma nova irmandade. Para Rich, a resistência ao casamento vista através da história era uma prática definidora que constituía o continuum lésbico. Monique Witting ${ }^{35}$ desenvolveu um argumento independente que do mesmo modo apontava a centralidade da heterossexualidade obrigatória na opressão das mulheres. Numa formulação que suas autoras viam como explicação para a ruptura decisiva com o marxismo tradicional do Mouvement pour la Libération des Femmes (MLF) na França, o grupo associado com Wittig argumentava que todas as mulheres pertencem a uma classe constituída pela relação social hierárquica de diferença sexual que dá aos homens poder ideológico, político e econômico sobre as mulheres (Editoras de Questions féministes,

\footnotetext{
${ }^{33}$ ID., IB., p.199.

${ }^{34} \mathrm{RICH}$, Adrienne. Compulsory Heterosexuality and Lesbian Existence. Signs 5 (4), 1980 .

${ }^{35}$ WitTIG, Monique. One is not Born a Woman. Feminist Issues 2, 1981.
} 
1989)..$^{36}$ O que faz uma mulher é uma relação específica de apropriação por um homem. Como raça, sexo é uma formação "imaginária" do tipo que produz realidade, inclusive corpos percebidos então como anteriores a toda construção. A "mulher" existe apenas como esta espécie de ser imaginário, enquanto as mulheres são produto de uma relação social de apropriação, naturalizada como sexo. Uma feminista é alguém que luta pelas mulheres enquanto classe e pela desaparição de tal classe. A luta principal é pela destruição do sistema social da heterossexualidade, porque "sexo" é a categoria política naturalizada que funda a sociedade como heterossexual. Todas as ciências sociais baseadas na categoria de "sexo" (a maioria delas)

\footnotetext{
${ }^{36}$ Várias correntes dos feminismos europeus (algumas desqualificando este título) nasceram depois dos eventos de maio de 1968. A corrente derivada das formulações de Simone de Beauvoir, especialmente o trabalho de Monique Wittig, Monique Plaza, Colette Guillaumin e Christine Delphy, publicava em Questions féministes, Nouvelles questions féministes e Feminist Issues e a corrente complexamente associada com o grupo "Psychanalyse et Politique" e/ou com Julia Kristeva, Luce Irigaray, Sarah Kofman e Hélène Cixous foram particularmente influentes na propagação, no feminismo internacional, das questões tratando da diferença sexual. (Para resumos introdutórios, ver MARKS, Elaine e DE COURTIVRON, Isabelle. (eds.) New French Feminism. Amherst, University of Massachusetts Press, 1980; GALloP, Jane. The Daughter's Seduction: Feminism and Psychoanalysis. New York, Macmillan, 1982; MoI, Toril. Sexual/Textual Politics. New York, Methuen, 1985; DuCHEN, Claire. Feminism in France from May '68 to Mitterrand. London, Routledge \& Kegan Paul, 1986.) Essas correntes merecem um tratamento mais amplo e em separado, mas no contexto deste verbete duas contribuições às teorias de "gênero" dessas escritoras, profundamente antagônicas entre si sobre exatamente essas questões, merecem ser assinaladas. Primeiro, há o argumento de Wittig e de Delphy a favor de um feminismo materialista, que insiste em que a questão é a "dominação" e não a "diferença". Segundo, há as várias maneiras de Irigaray, Kristeva e Cixous (alocadas intertextualmente em relação a Derrida, Lacan e outros) insistirem em que o sujeito, que talvez seja melhor percebido através da escrita e da textualidade, está sempre em processo, sempre estilhaçado, e que a idéia de mulher finalmente permanece aberta e múltipla. Apesar da importante oposição entre elas e no interior das correntes francófonas, todas essas teóricas têm projetos imperfeitos, contraditórios e críticos de desnaturalização da "mulher".
} 
"Gênero" para um dicionário marxista

devem ser destruídas. Neste sentido, as lésbicas não são "mulheres" porque estão fora da economia política da heterossexualidade. A sociedade lésbica destrói as mulheres enquanto grupo natural. ${ }^{37}$

Assim, teorizada a partir de três quadros distintos, a recusa ao casamento era central para a visão política de Rubin, Rich $e$ Wittig nos anos setenta e início dos oitenta. O casamento encapsulava e reproduzia a relação antagônica dos dois grupos sociais coerentes, homens e mulheres. Nas três formulações tanto o binarismo natureza/cultura como a dinâmica do producionismo impedia a continuação da análise. A retirada das mulheres da economia do casamento era uma figura potente e uma política de recusa aos homens e, assim, a favor da auto-constituição das mulheres como sujeitos pessoais e históricos fora da instituição da cultura dos homens na troca $e$ apropriação dos produtos (incluídos os bebês) das mulheres. Ser um sujeito no sentido ocidental significava reconstituir as mulheres fora das relações de reificação (como presente, mercadoria, objeto de desejo) e apropriação (de bebês, sexo, serviços).

A relação, definida como relação de categorias, entre homens e mulheres através da reificação, da troca e apropriação, que era a chave teórica para a categoria "gênero" na maior parte das obras da teoria feminista escrita pelas mulheres brancas nesse período, era um dos movimentos que tornava a compreensão do sistema raça/gênero ou do sistema raça/sexo e das barreiras à constituição de uma irmandade inter-racial difícil de apreender analiticamente pelas feministas brancas.

No entanto, essas formulações tiveram a poderosa virtude de destacar e legitimar o lesbianismo no coração do feminismo. A figura da lésbica esteve continuamente no centro disputado,

${ }^{37}$ Wittig, M. One is not Born a Woman. Op. cit. 
gerador, do debate feminista. ${ }^{38}$ Audre Lorde colocou a lésbica negra no centro de sua compreensão da "casa da diferença":

Ser mulheres juntas não era suficiente. Éramos diferentes. Ser garotas gays juntas não era suficiente. Éramos diferentes. Ser negras juntas não era suficiente. Éramos diferentes. Ser mulheres negras juntas não era suficiente. Éramos diferentes. Ser negras sapatonas juntas não era suficiente. Éramos diferentes... Levou algum tempo para percebermos que nosso lugar era a própria casa da diferença e não a segurança de alguma diferença em particular. ${ }^{39}$

Este conceito de diferença foi a base de boa parte da teoria feminista multi-cultural sobre gênero nos Estados Unidos no final dos anos oitenta.

Houve vários usos e críticas ao sistema de sexo-gênero de Rubin. Num artigo no centro de boa parte do debate marxista e socialista euro-americano, Hartmann insistia em que o patriarcado não era simplesmente uma ideologia como parecia argumentar Juliet Mitchell no seu seminal "Women: the Longest Revolution" ["Mulheres, a revolução mais longa"] e na sua ampliação em Women's Estate ${ }^{40}$, e sim um sistema material que podia ser definido como

\footnotetext{
${ }^{38}$ KING, Katie. The Situation of Lesbianism as Feminist's Magical Sign: Contests for Meaning and the U.S. Women's Movement, 1968-72. Communication 9 (1), 1984.

${ }^{39}$ LORDE, Audre. Zami, a New Spelling of My Name. Trumansberg, NY, Crossing, 1982 , p.226.

${ }^{40}$ MitcheLl, Juliet. Women: the Longest Revolution. New Left Review 40, 1966 [Mulheres, a revolução mais longa. Revista Civilização Brasileira (14), julho, 1967.] e Women's Estate. New York, Pantheon, 1971.
} 
"Gênero" para um dicionário marxista

um conjunto de relações sociais entre homens, que tem base material, e o qual, embora hierárquico, estabelece ou cria interdependência $e$ solidariedade entre os homens que os capacita a dominar as mulheres. ${ }^{41}$

Neste quadro, Hartmann tentou explicar a parceria do patriarcado e do capital $e$ a incapacidade dos movimentos trabalhistas socialistas, dominados por homens, em priorizar o sexismo. Hartmann utilizou o conceito de sistema de sexo-gênero de Rubin para reclamar a compreensão do modo de produção de seres humanos nas relações sociais patriarcais através do controle masculino da capacidade de trabalho das mulheres.

No debate estimulado pela tese de Hartmann, Iris Young criticava a abordagem "dualista" do capital e do patriarcado que eram vistos então como aliados na opressão de classe e gênero. Note-se que raça, incluindo um questionamento da posição racial dos brancos, permanecia um sistema inexplorado nessas formulações. Young argumentava que "as relações patriarcais estão internamente relacionadas às relações de produção como um todo" ${ }^{2}$, de tal modo que focalizar a divisão de trabalho por gênero poderia revelar a dinâmica de um único sistema de opressão. Além do trabalho assalariado, a divisão de trabalho por gênero incluía também as categorias de trabalho excluídas e não historicizadas em Marx e Engels, isto é, ter e criar crianças, cuidar dos doentes, cozinhar, o trabalho doméstico e trabalhos sexuais como a prostituição, de maneira a trazer gênero e a situação específica da mulher para o centro da análise materialistahistórica. Nesta teoria, já que a divisão de trabalho por gênero foi também a primeira divisão de trabalho, é preciso dar conta da emergência da sociedade de classes a partir das mudanças na divisão de trabalho por gênero. Tal análise não postula que todas

${ }^{41}$ Hartmann, H. The Unhappy Marriage of Marxism and Feminism. Op. cit., p.14.

${ }^{42}$ Young, Iris. Beyond the Unhappy Marriage: a Critique of the Dual Systems Theory. In: SARGENT, L. (ed.) Women and Revolution. Op.cit., p.49. 
as mulheres tenham uma situação comum, unificada, mas torna central as posições historicamente diferenciadas das mulheres. Se o capitalismo e o patriarcado são um sistema único, chamado patriarcado capitalista, então a luta contra a opressão de classe e de gênero deve ser unificada. A luta é obrigação de homens $e$ mulheres, embora a organização autônoma das mulheres permanecesse como uma necessidade prática. Esta teoria é um bom exemplo das abordagens modernistas, fortemente racionalistas, para as quais os movimentos "pós-modernos" de desagregação de metáforas de sistemas únicos em favor de complexos campos abertos com jogos de dominação, privilégio $e$ diferença que os atravessam pareciam bastante ameaçadores. $\mathrm{O}$ trabalho de 1981 de Young era também um bom exemplo do poder das abordagens modernistas de oferecer uma diretriz política em circunstâncias específicas.

Explorando as conseqüências epistemológicas de um materialismo histórico feminista, Nancy Hartsock ${ }^{43}$ também se concentrava nas categorias que o marxismo não tinha sido capaz de historicizar: (1) o trabalho sensorial das mulheres na produção de seres humanos através do parto e da criação de crianças; $e$ (2) o trabalho de nutrição e de subsistência de todos os tipos feitos pelas mulheres. Mas Hartsock rejeitou a terminologia da divisão de trabalho por gênero em favor da divisão sexual do trabalho, de modo a enfatizar as dimensões corporais das atividades das mulheres. Hartsock também criticava a formulação de Rubin do sistema de sexo-gênero porque ele enfatizava o sistema de trocas do parentesco a expensas de uma análise materialista dos processos de trabalho nos quais se baseava a construção de uma perspectiva revolucionária potencial das mulheres. Hartsock se apoiava em versões do humanismo-marxista enraizado na história da auto-formação humana nas mediações sensoriais da natureza e da humanidade através do trabalho. Ao mostrar como as vidas

${ }^{43}$ Hartsock, N. The Feminist Standpoint... Op. cit. e Money, Sex and Power.. Op. cit. 
"Gênero" para um dicionário marxista

das mulheres diferiam sistematicamente das dos homens, ela pretendia estabelecer o terreno para uma perspectiva feminista materialista que seria uma posição e uma visão engajadas, a partir das quais as relações reais de dominação poderiam ser desmascaradas, e desde onde se poderia lutar por uma realidade liberadora. Ela pedia que se explorassem as relações entre as abstrações da troca e a masculinidade abstrata nos hostis sistemas de poder que caracterizam os mundos falocráticos. Muitas outras feministas contribuíram para versões entrelaçadas e independentes da teoria feminista da perspectiva, na qual o debate sobre a divisão sexo/gênero do trabalho é um tema central. A progressiva problematização da categoria trabalho, ou suas extensões nos sentidos marxistas-feministas de reprodução, é fundamental para o debate, no esforço de teorizar uma atuação ativa e o estatuto das mulheres como sujeitos na história. ${ }^{44}$ Collins adaptou a teoria da perspectiva para caracterizar os fundamentos das idéias das feministas negras na perspectiva auto-definida das mulheres negras sobre sua própria opressão. ${ }^{45}$

Sandra Harding ${ }^{46}$ aproveitou o florescimento teórico do feminismo como expressão de um acirramento de contradições vividas no sistema de sexo-gênero, de modo que agora se pode lutar por mudanças fundamentais. Ampliando sua abordagem do sistema de sexo-gênero em The Science Question in Feminism ${ }^{47}$,

${ }^{44}$ SmITH, Barbara. (ed.) Home Girls: a Black Feminist Anthology. New York, Kitchen table, women of color press, 1983; FLAX, Jane. Political Philosophy and the Patriarchal Unconscious: a psychoanalytic perspective on epistemology and metaphysics. In: HARDING, S. e HinTIKKA, Merill. (eds.) Discovering Reality... Op. cit.; O'Brien, M. The Politics of Reproduction. Op. cit.; Rose, Hilary. Women's Work: Women's Knowledge. In: MitCHELl, Juliet and OAKLEY, Ann. (eds.) What Is Feminism? A Re-examination. New York, Pantheon, 1986, pp.161-183; HARDING, S. Why Has the Sex/Gender System... Op. cit.

${ }^{45}$ Coluins, Patricia Hill. The Social Construction of Black Feminist Thought. Signs 14 (4), 1989.

${ }^{46}$ Harding, S. Why Has the Sex/Gender System... Op. cit.

${ }^{47}$ ID. The Science Question in Feminism. Op. cit. 
Harding enfatizou três elementos de gênero, relacionados de maneiras diversas: (1) uma categoria fundamental através da qual se atribui sentido a tudo; (2) uma maneira de organizar as relações sociais e (3) uma estrutura de identidade pessoal. A desagregação desses três elementos tem sido parte da busca pela compreensão da complexidade e do valor problemático da política baseada em identidades de gênero. Utilizando o sistema de sexo-gênero para explorar a política de identidade sexual nos movimentos gays depois da Segunda Guerra, Jeffrey Escoffier ${ }^{48}$ argumentou a favor da necessidade de teorizar a emergência $e$ as limitações de novas formas de subjetividade política, de modo a desenvolver uma política envolvida, posicionada, sem limitações metafísicas de identidade. O "Manifesto para os Cyborgs", de Haraway ${ }^{49}$, desenvolvia argumentos semelhantes de modo a explorar a política marxista-feminista dirigida às posições das mulheres na ciência - e na tecnologia - multinacional, mediadas por sistemas sociais, culturais e técnicos.

Em outro desenvolvimento teórico devido ao marxismo, ao mesmo tempo que crítico dele e da linguagem de gênero, Catherine MacKinnon, argumentava que

A sexualidade é para o feminismo o que o trabalho é para o marxismo: o que é mais próprio de cada um e o que mais se tira de cada um... A sexualidade é este processo social que cria, organiza, expressa e direciona o desejo, criando os

\footnotetext{
${ }^{48}$ ESCOFFIER, Jeffrey. Sexual Revolution and the Politics of Gay Identity. Socialist Review 82/83, 1985.

${ }^{49}$ HaRaWAY, D. Manifesto for Cyborgs: Science, Technology, and Socialist feminism in the 1980s'. Socialist Review (80), 1985, pp.65-108; capitulo 8 de Simians, Cyborgs, and Women. Op. cit., pp.149-181. [Um manifesto para os cyborgs. ciência, tecnologia e feminismo socialista na década de 80. In: Hollanda, Heloisa Buarque de. (org.) Tendências e impasses: o feminismo como crítica da cultura. Rio de Janeiro: Rocco, 1994; ver também uma nova tradução em HaraWAY, Donna; KunzRU, Hari e SILVA, Tomaz Tadeu da. (org.) Antropologia do ciborgue. As vertigens do pós-humano. Belo Horizonte, Autêntica, 2000.]
} 
"Gênero" para um dicionário marxista

seres sociais que conhecemos como homens e mulheres, do mesmo modo como suas relações criam a sociedade... Assim como a expropriação organizada do trabalho de alguns para o benefício de outros define uma classe - a dos trabalhadores - a expropriação organizada da sexualidade de alguns para o uso de outros define o sexo, mulher. ${ }^{50}$

A posição de MacKinnon tem sido central nas abordagens controversas sobre a ação política em muitos dos movimentos norte-americanos contra a pornografia, definida como violência contra as mulheres e/ou como violação dos direitos civis das mulheres; isto é, a recusa às mulheres, através de sua construção como mulher, de seu estatuto de cidadá.

MacKinnon viu a construção da mulher como a construção material e ideológica do objeto de desejo do outro. Assim, as mulheres não são simplesmente alienadas do produto de seu trabalho; enquanto existem como "mulher", isto é, objeto sexual, elas não são sequer potencialmente sujeitos históricos. "Para as mulheres não há distinção entre reificação $e$ alienação porque as mulheres não são autoras de reificações, nós as temos sido". ${ }^{51}$ As conseqüências epistemológicas e políticas desta posição são enormes e têm sido extremamente controvertidas. Para MacKinnon, a produção de mulheres é a produção de uma ilusão bem material, "mulher". Desmanchar esta ilusão material, que é a realidade vivida das mulheres, requer uma política de conscientização, a forma específica da política feminista no quadro de MacKinnon. "A sexualidade determina o gênero", e "a sexualidade das mulheres é seu uso, assim como nossa feminilidade é sua alteridade" ${ }^{52}$ Como as formulações independentes nos feminismos lacanianos, a posição de Mackinnon tem sido importante em teorizar processos de

${ }^{50}$ MacKInNON, Catherine. Feminism, Marxism, Method and the State: an Agenda for Theory. Signs 7 (3), 1982, p.515.

${ }^{51}$ ID., IB., pp.253-4.

${ }^{52}$ ID., IB., p. 243 
representação nos quais o "poder de criar o mundo da perspectiva de alguém é o poder na sua forma masculina". ${ }^{53}$

Numa análise da violência em termos de gênero, afim à análise de MacKinnon, mas baseada em fontes teóricas e políticas diferentes, as abordagens de Teresa de Lauretis ${ }^{54}$ sobre a representação a levaram a analisar gênero como a trágica falha das teorias modernas e pós-modernas da cultura, cujo problema é o contrato heterossexual. De Lauretis definiu gênero como a construção social de "mulher" e "homem" e a produção semiótica da subjetividade; gênero tinha a ver com "a história, as práticas e a imbricação de sentido e experiência", isto é, com "os efeitos constitutivos mútuos na semiose do mundo exterior da realidade social com o mundo interior da subjetividade". ${ }^{55}$ De Lauretis utilizou as teorias de Charles Pierce sobre a semiótica para desenvolver uma abordagem da "experiência", uma das noções mais problemáticas do feminismo moderno, que leva em conta tanto as incorporações íntimas da experiência quanto suas mediações através de práticas significativas. A experiência nunca é imediatamente acessível. Seus esforços tem sido particularmente úteis na compreensão e na contestação das inscrições de gênero no cinema e em outras áreas nas quais a idéia de que gênero é uma diferença semiótica corporificada é crucial e fonte de poder. Diferenciando as tecnologias de gênero das formulações de Foucault sobre as tecnologias do sexo, De Lauretis identificou uma posição de um sujeito feminista específico, marcado pelo gênero, no sistema de sexo/gênero. Sua formulação evoca a compreensão de Lorde dos habitantes da casa das diferenças:

\footnotetext{
${ }^{53}$ ID., IB., p.249.

${ }^{54}$ DE LAURETIS, Teresa. Alice doesn't: Feminism, Semiotics, Cinema. Bloomington, Indiana University Press, 1984 e The Violence of Rethoric: Considerations on Representation and Gender. Semiotica 54, 1985.

${ }^{55}$ DE LAURETIS, T. Alice doesn't... Op. cit., pp.158-86.
} 
"Gênero" para um dicionário marxista

O sujeito feminino do feminismo é construído através de uma multiplicidade de discursos, posições e sentidos, freqüentemente em conflito uns com os outros $e$ inerentemente (historicamente) contraditório. ${ }^{56}$

Oferecendo uma teoria da consciência e da produção de sentido bem diferente da de MacKinnon ou de Lauretis, a exploração feita por Hartsock ${ }^{57}$ da divisão sexual do trabalho inspirou-se nas versões anglófonas da psicanálise que foram particularmente importantes na teoria feminista norte-americana, isto é, a teoria das relações objetais, desenvolvida especialmente por Nancy Chodorow. ${ }^{58}$ Sem adotar as teorias lacanianas de Rubin de uma subjetividade sexuada sempre fragmentada, Chodorow adotou o conceito de sistema de sexo-gênero em seu estudo da organização social da educação na família, que produz as mulheres como mais capazes de relações não hostis do que os homens, mas que também perpetua a posição subordinada das mulheres por meio de sua produção como pessoas estruturadas para a maternidade no patriarcado. A preferência pela psicanálise das relações objetais contra a versão lacaniana relaciona-se com conceitos vizinhos como "identidade de gênero", com sua rede de significados da ciência social empírica, que é diferente da "aquisição de posições de subjetividade sexuada", conceito este imerso na teoria cultural/textual do continente. Embora criticada como uma teoria essencializadora da mulher-como-relacional, a teoria das relações objetais de Chodorow teve grande influência e foi adaptada para a exploração de uma ampla gama de fenômenos sociais. Utilizando-se das teorias neo-kantianas de Lawrence Kohlberg, e criticando-as, Gilligan ${ }^{59}$ também

${ }^{56}$ ID. Technologies of Gender: Essays on Theory, Film, and Fiction. Bloomington, Indiana University Press, 1987, pp.ix-x.

${ }^{57}$ HaRTSOCK, N. The Feminist Standpoint... Op. cit.

${ }^{58}$ CHOdOROW, N. The Reproduction of Mothering... Op. cit.

${ }^{59}$ Gilligan, Carol. In a Different Voice. Cambridge, Ma, Harvard University Press, 1982. 
argumentou a favor da maior consciência contextual das mulheres $e$ de sua resistência a abstrações universalizantes, como nos raciocínios morais.

Evelyn Keller desenvolveu uma versão da teoria das relações objetais para teorizar a dominação masculina sistemática, em termos epistemológicos, psíquicos e organizacionais na ciência natural. ${ }^{60}$ Keller antecipou o equívoco lógico de igualar mulher e gênero. ${ }^{61}$ Gênero é um sistema de relações sociais, simbólicas e psíquicas no qual homens e mulheres estão diferentemente alocados. Observando a expressão de gênero como uma experiência cognitiva na qual a individuação psíquica masculina produz um investimento na impessoalidade, na reificação $e$ na dominação, Keller descreveu seu projeto como um esforço para compreender o "sistema de ciência-gênero". ${ }^{2}$ Enfatizando a construção social e concentrando-se nos aspectos psicodinâmicos dessa construção, Keller tomou como sujeitos

não mulheres per se, nem mulheres e ciência: mas a construção de homens, mulheres e da ciência ou, mais precisamente, como a construção de homens e mulheres afetou a construção da ciência. ${ }^{63}$

Seu objetivo era trabalhar em prol da ciência como um projeto humano, não um projeto masculino. Ela expressou sua questão

${ }^{60}$ KeLler, Evelyn Fox. Reflections on Gender and Science. New Haven, Yale University Press, 1985.

${ }^{61}$ De modo análogo, é um erro igualar "raça" com pessoas de cor; a brancura é também uma construção racial, invisível como tal dada sua ocupação da categoria não marcada. FRANKENBERG, Ruth. The Social Construction of Whiteness. Tese de Doutorado, University of California, Santa Cruz, 1988; CARBY, Hazel. Reconstructing Womanhood: the Emergence of the Afro-American Woman Novelist. New York, Oxford University Press, 1987, p.18; HARAWAY, Donna J. Primate Visions: Gender, Race, and Nature in the World of Modern Science. New York, Routledge, 1989, pp.152, 401-402.

${ }^{62}$ KeLLER, E. F. Reflections on Gender and Science... Op. cit., p.8.

${ }^{63}$ ID., IB., p.4. 
"Gênero" para um dicionário marxista

como: "Sexo está para gênero assim como a natureza está para a ciência?". ${ }^{64}$

O trabalho inicial de Chodorow foi desenvolvido no contexto de uma série de outros trabalhos sociológicos e antropológicos relacionados que postulavam um papel central para a divisão público/privado na subordinação das mulheres. ${ }^{65}$ Nessa coletânea, Rosaldo chamava a atenção para um ponto universal, a limitação das mulheres ao espaço doméstico, ao passo que o poder estava investido no espaço habitado pelos homens, chamado público. Sherry Ortner relacionou esta abordagem a sua análise estruturalista da proposta de que as mulheres estão para a natureza assim como os homens estão para a cultura. Boa parte dos esforços feministas euro-americanos de articulação da posição social das mulheres, que se seguiram à Woman, Culture and Society [Mulher, cultura e sociedade] e a Toward an Anthropology of Women ${ }^{66}$, ambas estrategicamente publicadas nos meados dos anos setenta, foram profundamente influenciados pelas teorias universalizantes e poderosas dessas primeiras coletâneas. Na antropologia como disciplina, a crítica e outros desenvolvimentos das primeiras formulações foram ricos, levando tanto a um amplo estudo transcultural dos simbolismos de gênero quanto a uma rejeição fundamental da utilização universal do par naturezacultura. No interior das disciplinas, havia uma crítica crescente à explicação universalizante como exemplo do equívoco de confundir a realidade com a ferramenta analítica. ${ }^{67}$ Enquanto a

${ }^{64}$ ID. The Gender/Science System: or, Is Sex to Gender as Nature is to Science?. Hypatia 2(3), 1987.

${ }^{65}$ Rosaldo, Michelle e LAMPHERE, Louise. (eds.) Woman, Culture and Society. Palo Alto, Stanford University Press, 1974. [Mulher, cultura e sociedade. Rio de Janeiro, Paz e Terra, 1979.]

${ }^{66}$ ReITER, Rayna Rapp. (ed.) Toward an Anthropology of Women. Op. cit.

${ }^{67}$ MacCormack, Carol e Strathern, Marilyn. (eds.) Nature, Culture, Gender. Cambridge, Cambridge University Press, 1980; Rosaldo, Michelle. The Use and Abuse of Anthropology. Signs 5, 1980. [O uso e abuso da antropologia: reflexões sobre o feminismo e o entendimento inter-cultural. Horizontes Antropológicos 
antropologia feminista se afastava de suas formulações iniciais, elas, não obstante, persistiram em muitos discursos feministas fora dos círculos antropológicos, como se as posições de meados dos anos setenta fossem uma teoria feminista antropológica permanentemente autorizada e não um nódulo discursivo num momento específico político-histórico-disciplinar.

$\mathrm{O}$ poder universalizante do sistema sexo-gênero e a ruptura analítica entre o público e o privado foram também agudamente criticados politicamente, particularmente pelas mulheres de cor, como parte das tendências etnocêntricas e imperialistas dos feminismos europeus e euro-americanos. A categoria gênero obscurecia ou subordinava todos os outros "outros". Os esforços para utilizar conceitos ocidentais, ou "brancos", de gênero, para caracterizar a "mulher do Terceiro Mundo" freqüentemente resultaram na reprodução do discurso orientalista, racista $e$ colonialista. ${ }^{68}$ Além disso, as "mulheres de cor" norte-americanas, elas próprias uma construção política complexa e contestada de identidades sexuadas, produziram teoria crítica sobre a produção de sistemas de diferenças hierárquicas nas quais raça, nacionalidade, sexo e classe estavam entrelaçados, tanto no século dezenove e no início do século vinte, como desde o início dos movimentos de mulheres que emergiram dos movimentos pelos direitos civis e contra a guerra nos anos sessenta. ${ }^{69}$ Essas

(1), Porto Alegre, Universidade Federal do Rio Grande do Sul, 1995.]; ORTNER, Sherry B. e WHITEHEAD, Harriet. Sexual Meanings: the Cultural Construction of Gender and Sexuality. Cambridge, Cambridge University Press, 1981; RUBIN, Gayle. Thinking Sex: Notes for a Radical Theory of the Politics of Sexuality. In: VANCE, Carol. (ed.) Pleasure and Danger. London, Routledge \& Kegan Paul, 1984.

${ }^{68}$ MOHANTY, Chandra Talpade. Under Western Eyes: Feminist Scholarship and Colonial Discourse. Boundary 2,3, 1984; AmOS, Valerie; LEWIS, Gail; MAMA, Amina e PARMAR, Pratibha. (eds.) Many Voices, one Chant: Black Feminist Perspectives. Feminist Review (17), 1984.

${ }^{69}$ Ver, por exemplo, WARE, Celestine. Woman Power. New York, Tower, 1970; Combahee River collective. A Black Feminist Statement. In: EISESTEIN, Zilah. (ed.) Capitalist Patriarchy and the Case for Socialist Feminism. New York, Monthly 
"Gênero" para um dicionário marxista

teorias sobre o posicionamento social das mulheres formam a base e organizam a teoria feminista "genérica" na qual conceitos como "a casa da diferença"70, "consciência oposicional"71, "mulherismo" (womanism) ${ }^{72}$, "lançada do centro

Review, 1979; BetHEL, Lorraine e SMITH, Barbara. (eds.) The Black Women's Issue. Conditions 5, 1979; JOSEPH, Gloria e LEWIS, Jill. Common Differences. New York, Anchor, 1981; HOOKS, bell. Ain't I a Woman. Boston, South End, 1981; HOOKS, bell. Feminist theory: From Margin to center. Boston, South End, Hooton, E.A., 1984. Up from the Ape, New York, Macmillan, 1931; MoraGA, Cherríe e ANZALDÚA, Gloria (eds.) This Bridge Called My Back: Writing by Radical Women of Color. Watertown, Persephone, 1981; DAVIS, Angela. Women, Race and Class. London, Women's Press, 1982; Hull, Gloria, ScOTT, Patricia Bell e SMITH, Barbara. (eds.) All the Women are White, all the Men are Black, but some of us are Brave. Old Westbury, The Feminist Press, 1982; LORDE, Audre. Zami... Op. cit. e Sister Outside. Trumansberg, NY, Crossing, 1984; APTHEKER, Betina. Woman's Legacy: Essays on Race, Sex, and Class in American history. Amherst, Un. of Massachusetts Press, 1982; MoRAGA, Cherríe. Loving in the War Years: lo que nunca pasó por sus labios. Boston, South End, 1983; WALKER, Alice. In Search of our Mother's Gardens. New York, Harcourt, Brace, Jovanovitch, 1983; SMITH, B. (ed.) Home Girls... Op. cit.; BULKIN, Elly, PRATT, Minnie Bruce e SMITH, Barbara. Yours in Struggle: Three Feminist Perspectives on Racism and Anti-Semitism. New York, Long Haul, 1984; SANDOVAL, Chela. Yours in Struggle: Women Respond to Racism, a Report on the National Women's Studies Association. Oakland, Ca, Center for Third World Organizing, s/d; CHRISTIAN, Barbara. Black Feminist Criticism: Perspectives on Black Women Writers. New York, Pergamon, 1985; GidDings, Paula. When and Where I Enter: the Impact of Black Women on Race and Sex in America. Toronto, Bantam, 1985; ANZALdúA, Gloria. Borderland/La Frontera. San Francisco, Spinsters/Aunt Lute, 1987; CARBY, H. Reconstructing Womanhood... Op.cit.; SPILlERS, Hortense. Mama's Baby, Papa's Maybe: an American Gramar Book. Diacritics 17 (2), 1987; Collins, P. H. The Social Construction of Black Feminist Thought. Op. cit. e A Comparison of Two Works on Black Family Life. Signs 14 (4), 1989; HuRTADO, Aida. Relating to Privilege: Seduction and Rejection in the Subordination of White Women and Women of Color. Signs 14 (4), 1989.

${ }^{70}$ LoRDE, A. Zami... Op. cit. E ...

${ }^{71}$ SANDOVAL, Chela. Yours in Struggle... Op. cit.

${ }^{72}$ WALKER, Alice. In Search of our Mother's Gardens. Op. cit. 
para a margem"73, "Feminismo do Terceiro Mundo"74, "el mundo zurdo"75, "la mestiza"76, "capitalismo patriarcal racialmente estruturado"77 e "outro impróprio/não-apropriado"78 estruturam o campo do discurso feminista à medida que ele decodifica o que significa "mulher" no interior e fora do "feminismo". Figuras complexamente relacionadas com essas também emergiram nos escritos feministas de mulheres "brancas": "classes sexopolíticas"79; "ciborgue" ${ }^{80}$; "o sujeito fêmea do feminismo". ${ }^{81}$

No início dos anos oitenta, a Kitchen Table: Women of Color Press [Mesa de Cozinha: Editora das Mulheres de Cor] foi criada em Nova Iorque e começou a publicar a teoria crítica e outros textos das mulheres de cor radicais. Este acontecimento deve ser visto no contexto da publicação internacional de vários gêneros literários feita pelas mulheres que escreviam em sua consciência as estórias de suas construções, dessa forma desestabilizando os cânones do feminismo ocidental, bem como os de vários outros discursos. Conforme as posições de sujeito das "mulheres de cor", heterogêneas e críticas, eram progressivamente

73 SPIVAK, Gayatri. Three women's texts and a critique of imperialism. Critical Inquiry (12) I, 1985, pp.243-61.

${ }^{74}$ Moraga, Cherríe. Loving in the War Years... Op. cit.; SmITH, Barbara. (eds.) All the Women are White... Op. cit.

${ }^{75}$ Moraga, C. e AnZaldúA, G. (eds.) This Bridge Called My Back... Op.cit.

${ }^{76}$ AnZALdÚA, G. Borderland/La Frontera. Op. cit.

${ }^{77}$ BHAVNANI, Kum-Kum e Coulson, Margaret. Transforming Socialist-Feminism: the Challenge of Racism. Feminist Review 23, 1986.

${ }^{78}$ TRINH, T. Minh-ha. "Introduction" and Difference: a Special Third World Women Issue. Discourse, journal for theoretical studies in media and culture 8, 1986-7; TRINH, T. Minh-ha. (ed.) She, the Inappropriate/d Other. Discourse 8, 1986-7 e Woman, Native, Other: Writing Postcoloniality and Feminism. Bloomington, Indiana University Press, 1989.

${ }^{79}$ Sofoulis, Zoe. Lacklein. Universidade da Califórnia, Santa Cruz, 1987, ensaio não publicado.

${ }^{80}$ HaRAWAY, D. Manifesto for Cyborgs... Op. cit.

${ }^{81}$ DE LAURETIS, T. Technologies of Gender... Op. cit. 
"Gênero" para um dicionário marxista

elaboradas através de diversas práticas editoriais, o estatuto de "branco" ou "ocidental" também era mais prontamente visto como uma alocação contestável e não como uma etnia ou raça dada ou como um destino inescapável. Assim, as mulheres "brancas" podiam ser chamadas a prestar contas de suas posições ativas.

A teoria do sistema de sexo/gênero de Rubin, de 1975, explicava a complementaridade dos sexos (heterossexualidade obrigatória) e a opressão das mulheres pelos homens através da premissa central da troca de mulheres na fundação da cultura por meio do parentesco. Mas o que acontece com esta abordagem quando as mulheres não são alocadas desta forma na instituição do parentesco? E, em particular, o que acontece com a idéia de gênero se grupos inteiros de mulheres e de homens são alocados fora da instituição do parentesco, mas em relação aos sistemas de parentesco de outro grupo, o grupo dominante? Carby, Spillers e Hurtado $^{82}$ questionaram o conceito de gênero através de uma exploração da história e das conseqüências desses temas.

Carby mostrou como no Novo Mundo, e particularmente nos Estados Unidos, as mulheres negras não foram constituídas como "mulher", como o foram as mulheres brancas. As mulheres negras foram simultaneamente constituídas, racial e sexualmente como fêmea marcada (animal, sexualizada, e sem direitos), mas não como mulher (humana, esposa potencial, conduto para o nome do pai) - numa instituição específica, a escravidão, que as excluía da "cultura" definida como a circulação de signos através do sistema de casamento. Se o parentesco investia os homens com direitos sobre as mulheres que elas próprias não detinham sobre si mesmas, a escravidão aboliu o parentesco para um grupo num discurso legal que produziu grupos inteiros de pessoas como propriedade alienável. ${ }^{83}$ MacKinnon definiu a mulher como uma

${ }^{82}$ CARBY, H. Reconstructing Womanhood... Op.cit.; SPILlERS, H. Mama's Baby, Papa's Maybe... Op.cit.; HURTADO, A. Relating to Privilege... Op.cit.

83 SPILlERS, H. Mama's Baby, Papa's Maybe... Op.cit. 
figura imaginária, objeto de desejo do outro, tornada real. ${ }^{84}$ As figuras "imaginárias" tornadas reais no discurso escravista eram objetos num outro sentido que as tornava diferentes tanto da figura marxista do trabalhador alienado como da figura feminista "não modificada" do objeto do desejo. No patriarcado branco norte-americano, as mulheres livres eram trocadas num sistema que as oprimia, mas as mulheres brancas herdavam mulheres $e$ homens negros. Como Hurtado observou, no século dezenove as feministas brancas notáveis eram casadas com homens brancos, enquanto as feministas negras eram propriedade dos homens brancos. ${ }^{85}$ Num patriarcado racista, a "necessidade" de filhos racialmente puros, por parte dos homens brancos, colocava as mulheres livres $e$ as não livres em espaços incompatíveis, simbólica e socialmente assimétricos.

A escrava era marcada por essas diferenças de um modo mais literal - a carne era virada do avesso, "acrescentando uma dimensão léxica às narrativas da mulher na cultura $e$ na sociedade". "Essas diferenças não terminaram com a abolição formal; elas têm tido conseqüências definitivas até o final do século vinte e continuarão a ter até que o racismo como uma instituição fundadora do Novo Mundo tenha acabado.

Spillers chamou essas relações fundadoras de cativeiro $e$ mutilação literal de "uma gramática americana". ${ }^{87}$ Nas condições da conquista do Novo Mundo, da escravidão e de suas conseqüências até o presente, "o léxico da reprodução, do desejo, da nominação, da maternidade, da paternidade, etc. é lançado numa profunda crise". ${ }^{88}$

${ }^{84}$ MaCKInNON, C. Feminism, Marxism, Method and the State... Op. cit. $e$ Feminism Unmodified: Discourses on Life and Law. Cambridge, Ma, Harvard University Press, 1987.

${ }^{85}$ HuRTADO, A. Relating to Privilege... Op.cit., p.841.

${ }^{86}$ SPILlers, H. Mama's Baby, Papa's Maybe... Op.cit., pp.67-8.

${ }^{87}$ ID., IB., p. 68.

${ }^{88}$ ID., IB., p. 76. 
"Gênero" para um dicionário marxista

A marca de gênero, na sua referência coeva às mulheres Afro-americanas, insinua um enigma implícito e não resolvido tanto no interior do discurso feminista corrente como no interior dessas comunidades discursivas que investigam a problemática da cultura. ${ }^{89}$

Spillers apontou para o fato de que homens e mulheres livres herdavam seu nome do pai o qual, por seu turno, tinha direitos sobre seus filhos menores e sobre sua esposa que eles próprios não tinham sobre si mesmos, mas ele não era proprietário deles no sentido completo de propriedade alienável. Homens e mulheres não livres herdavam sua condição de sua mãe a qual, por seu turno, especificamente não controlava seus filhos. Eles não tinham nome no sentido apontado por LéviStrauss ou Lacan. Mães escravas não podiam transmitir um nome; não podiam ser esposas; elas estavam fora do sistema de troca matrimonial. Os escravos não tinham posição, não estavam fixados, num sistema de nomes; eles eram, especificamente, não alocados e portanto disponíveis. Nesses quadros discursivos, as mulheres brancas não eram, legal ou simbolicamente, inteiramente humanas; os escravos não eram humanos nem legal, nem simbolicamente. "Nessa ausência de uma posição de sujeito, as sexualidades capturadas oferecem uma expressão física $e$ biológica de alteridade" ${ }^{90}$ Dar à luz (sem ser livre) ao herdeiro da propriedade não é a mesma coisa que dar à luz (sem ser livre) à propriedade. $^{91}$

Esta pequena diferença é parte da razão pela qual os "direitos reprodutivos" para as mulheres de cor nos Estados Unidos giram principalmente em torno do controle geral das crianças - liberá-las, por exemplo, da destruição causada por linchamentos, prisão, mortalidade infantil, gravidez forçada,

\footnotetext{
${ }^{89}$ ID., IB., p.78.

${ }^{90}$ ID., IB., Op.cit., p.67.

${ }^{91}$ CARBY, H. Reconstructing Womanhood... Op.cit., p.53.
} 
esterilização coercitiva, moradias inadequadas, educação racista ou o vício de drogas. ${ }^{92}$ Para as mulheres brancas, o conceito de propriedade do eu, o ser dona do próprio corpo, em relação à liberdade reprodutiva, tem sido em geral focalizado no campo de eventos em torno da concepção, da gravidez, do aborto $e$ do nascimento, porque o sistema patriarcal branco dedicou-se ao controle dos filhos legítimos e, como conseqüência, da constituição das fêmeas brancas como mulheres. Ter ou não ter filhos torna-se então para as mulheres, literalmente, uma escolha que define o sujeito. As mulheres negras particularmente $-e$ as mulheres submetidas à conquista do Novo Mundo em geral - se defrontaram com um campo social mais amplo de falta de liberdade reprodutiva no qual seus filhos não herdaram o estatuto de humanos nos discursos hegemônicos fundadores da sociedade norte-americana. O problema da mãe negra nesse contexto não é simplesmente seu próprio estatuto como sujeito, mas também o estatuto de seus filhos e de seus parceiros sexuais, machos $e$ fêmeas. Não é de admirar, portanto, que a imagem de "fazer progredir" a raça e a recusa da separação categórica entre homens e mulheres - sem deixar de lado a análise da opressão sexista branca ou negra - tenham sido centrais no discurso feminista negro no Novo Mundo. ${ }^{93}$

O posicionamento das mulheres Afro-americanas não é o mesmo do de outras mulheres de cor; cada condição de opressão requer análise específica que recusa a separação, mas insiste na não identidade de raça, sexo e classe. Essas questões tornam perfeitamente claro porque uma teoria feminista de gênero adequada deve simultaneamente ser uma teoria da diferença racial nas condições históricas específicas de produção $e$ reprodução. Também tornam claro porque uma teoria e uma prática da sororidade não podem estar apoiadas em

${ }^{92}$ HuRTAdo, A. Relating to Privilege... Op.cit., p.853.

${ }^{93}$ CARBY, H. Reconstructing Womanhood... Op.cit., pp.6-7; HOOKS, bell. Ain't I a Woman. Op. cit. e Feminist theory... Op. cit. 
"Gênero" para um dicionário marxista

posicionamentos compartilhados num sistema de diferença sexual e no antagonismo estrutural entre categorias coerentes chamadas mulheres e homens consideradas transculturalmente. Por último, tornam claro também porque a teoria feminista produzida pelas mulheres de cor construiu discursos alternativos sobre a mulher que disromperam o humanismo de várias tradições discursivas ocidentais.

É nossa tarefa encontrar um lugar para este sujeito social diferente. Ao fazê-lo estamos menos interessadas em juntarnos às fileiras da feminilidade marcada pelo gênero do que em ganhar um terreno insurgente como sujeitos sociais femininos. Realmente exigindo a monstruosidade de existir uma fêmea com o potencial de "nomear"... "Safira" pode, afinal, re-escrever um texto de poder feminino radicalmente diferente. ${ }^{94}$

Ao mesmo tempo que contribui fundamentalmente para a quebra da alocação de qualquer sujeito como patrão, a política da "diferença" que emerge dessas e de outras complexas reconstruções de conceitos de subjetividade social e as práticas de escrita a ela associadas opõe-se profundamente aos relativismos niveladores. A teoria não feminista nas ciências humanas tem a tendência a identificar a quebra da subjetividade dominadora ou "coerente" como "a morte do sujeito". Como outros em posições recém instavelmente conquistadas, muitas feministas resistem a essa formulação do projeto e questionam sua emergência justamente no momento em que os falantes marcados por raça/sexo/colonização aparecem "pela primeira vez", isto é, reclamam uma autoridade original de representar a si mesmos em práticas institucionalizadas de publicação e em outros tipos de práticas de auto-constituição. As desconstruções feministas do "sujeito" foram fundamentais, e elas não têm saudades da coerência dominadora. Ao invés disso, relatos políticos de

${ }^{94}$ SPILleRs, H. Mama's Baby, Papa's Maybe... Op.cit., p.80. 
corporificações construídas, como as teorias feministas de subjetividades marcadas por gênero e raça, têm, necessariamente, de levar em conta, afirmativa e criticamente, subjetividades sociais emergentes, diferenciadas, auto-representadas, contraditórias, com suas exigências de ação, conhecimento e crença. Isto implica no compromisso com a mudança social transformadora, o momento de esperança embutido nas teorias feministas de gênero e em outros discursos emergentes a respeito da quebra da subjetividade dominadora e na emergência de outros impróprios/nãoapropriados. ${ }^{95}$

As múltiplas raízes, acadêmicas e de outras instituições, feministas e outras, da categoria literal (escrita) "gênero", esboçada neste verbete, são parte do sistema de relações racialhierárquico que ofusca as publicações das mulheres de cor por causa de sua origem, linguagem, gênero literário - em suma, "marginalidade", "alteridade" e "diferença" vistas desde uma posição "não-marcada" da teoria hegemônica e imperializante ("branca"). Mas é precisamente da "alteridade" e da "diferença" de que "gênero" trata "gramaticalmente", um fato que constitui o feminismo como uma política definida por seus campos de contestação e repetidas recusas das teorias dominadoras. "Gênero" foi desenvolvido como uma categoria para explorar o que significa "mulher", para problematizar o que era anteriormente dado. Se as teorias feministas de gênero partiram da tese de Simone de Beauvoir de que não se nasce mulher, com todas as conseqüências dessa percepção, à luz do marxismo e da psicanálise, para a compreensão de que qualquer sujeito inteiramente coerente é uma fantasia, e que a identidade pessoal $e$ coletiva é precária e constantemente socialmente reconstituída ${ }^{96}$, então o título do provocativo livro de bell hooks, evocando a grande feminista e abolicionista negra do século dezenove,

${ }^{95}$ TRINH, T. M. "Introduction", and Difference... Op. cit.; TRINH, T. M. (ed.) She, the Inappropriate... Op. cit.; e Woman, Native, Other... Op. cit.

${ }^{96}$ CowARD, R. Patriarchal precedents... Op. cit., p.265. 
"Gênero" para um dicionário marxista

Sojourner Truth, Ain't I a woman [Não sou mulher?] ${ }^{97}$, está carregado de ironia, já que a identidade de "mulher" é simultaneamente exigida e desconstruída. A luta sobre os agentes, as memórias e os termos dessas reconstituições é o coração da política feminista de sexo/gênero.

A recusa em tornar-se ou permanecer homem ou mulher marcado/a pelo gênero é, então, uma insistência eminentemente política em sair do pesadelo da muito-real narrativa imaginária de sexo e raça. Finalmente, e ironicamente, o poder político e explicativo da categoria "social" de gênero depende da historicização das categorias de sexo, carne, corpo, biologia, raça e natureza, de tal maneira que as oposições binárias, universalizantes, que geraram o conceito de sistema de sexo/gênero num momento e num lugar particular na teoria feminista sejam implodidas em teorias da corporificação articuladas, diferenciadas, responsáveis, localizadas e com conseqüências, nas quais a natureza não mais seja imaginada $e$ representada como recurso para a cultura ou o sexo para o gênero.

Aqui está minha alocação para uma intersecção utópica das teorias feministas de gênero, heterogêneas, multi-culturais, "ocidentais" (de cor, branca, européia, americana, asiática, africana, do Pacífico), que foram chocadas na estranha irmandade com dualismos binários herdados, contraditórios, hostis, frutíferos. O falogocentrismo foi ovulado pelo sujeito dominador, o galo inseminador das galinhas permanentes da história. Mas no ninho com este ovo prosaico foi posto o germe de uma fênix que falará todas as línguas de um mundo virado de ponta cabeça.

${ }^{97}$ HOOKS, bell. Ain't I a Woman. Op. cit. 